\title{
THE CARDIOHEMODYNAMIC EFFECTS OF VENOUS CONGES- TION OF THE LEGS OR OF PHLEBOTOMY IN PATIENTS WITH AND WITHOUT CONGESTIVE HEART FAILURE ${ }^{1}$
}

\author{
By WALTER E. JUDSON, WILLIAM HOLLANDER,² J. D. HATCHER, ${ }^{3}$ MEYER H. \\ HALPERIN, AND IRWIN H. FRIEDMAN * \\ (From the Robert Dewson Evans Memorial Department of Clinical Research and Preventive \\ Medicine, Massachusetts Memorial Hospitals, and the Department of Medicine, Boston \\ University School of Medicine, Boston, Mass.)
}

(Submitted for publication May 18, 1954; accepted by December 29, 1954)

The purpose of this study was to clarify the cardiohemodynamic responses to acute reduction in the "effective circulating blood volume" in man. McMichael and Sharpey-Schafer found that the cardiac output in normal subjects fell during venous congestion of the extremities (1). They attributed this reduction in cardiac output to a decrease in the right atrial pressure. Their observation that right atrial pressure usually falls during such acute reductions in the "effective circulating blood volume" was confirmed by Warren, Brannon, Stead, and Merrill (2), but these latter workers did not usually find an associated decrease in cardiac output. They therefore suggested that the cardiac output response is independent of changes in right atrial pressure, at least within physiological limits. However, observations by Howarth, McMichael, and SharpeySchafer (3) on the effects of phlebotomy and of venous congestion of the extremities in patients with congestive heart failure supported the concept that the level of right atrial pressure is an important factor in determining cardiac output. The studies reported herewith differ in certain aspects from all those just mentioned.

\section{MATERIAL AND METHODS}

The patients in Group I had neither clinical nor hemodynamic evidence of cardiac insufficiency at rest or af-

1 This investigation was supported in part by a grant from the National Heart Institute of the National Institutes of Health, U. S. P. H. S.

2 United States Public Health Service Fellow in Medicine, Evans Memorial, Massachusetts Memorial Hospitals.

8 Formerly Fellow in Medicine, Evans Memorial, Massachusetts Memorial Hospitals. Present Address : Queen's University, Kingston, Ontario, Canada.

* Formerly United States Public Health Service Fellow in Medicine, Evans Memorial, Massachusetts Memorial Hospitals. Present Address: East Meadow, New York. ter exercise. They included two normal subjects, one with essential hypertension, and two with hypertensive cardiovascular disease. Group II-A contained patients with non-valvular types of heart disease with congestive failure and included three patients with hypertensive cardiovascular disease and two with arteriosclerotic heart disease. Group II-B contained patients with valvular types of heart disease and congestive failure and included five with rheumatic heart disease and one with syphilitic heart disease. All of the patients in Group II-A and $B$ were considered to be in congestive failure on the basis of their clinical cardiovascular symptoms and signs and their abnormal hemodynamic responses during exercise. Furthermore, all of the patients were taking digitalis, and several were receiving mercurial or other diuretics for treatment of their congestive failure. Group III consisted of patients with pulmonary emphysema, two of whom had cor pulmonale with congestive heart failure and two of whom had pulmonary hypertension with no evidence of right ventricular hypertrophy or failure.

\section{PROCEDURE}

The patients were studied in the post-absorptive state without any preliminary sedative medication. A doublelumen intracardiac catheter was inserted into the right heart so that simultaneous records of the pulmonary arterial and right ventricular pressures could be obtained. An indwelling needle was maintained in the brachial artery. All pressures were measured with electromanometers $^{5}$ and recorded by direct-writing oscillograph; the zero point of reference for all pressures was $10 \mathrm{~cm}$. above the back of the supine subject. Mean pressures were determined by electrical integration. Using criteria which are comparable with those in Cournand's laboratory, reductions in either the right ventricular diastolic or mean pulmonary arterial pressures of $5 \mathrm{~mm}$. $\mathrm{Hg}$ or more were considered physiologically significant, while changes in the mean systemic arterial pressure of $15 \mathrm{~mm}$. $\mathrm{Hg}$ were also judged physiologically significant (4).

The resistances were calculated, according to Gorlin and his co-workers (5), by the following formulae:

The "total pulmonary" resistance (actually, total

s Sanborn Co., Cambridge, Massachusetts. 


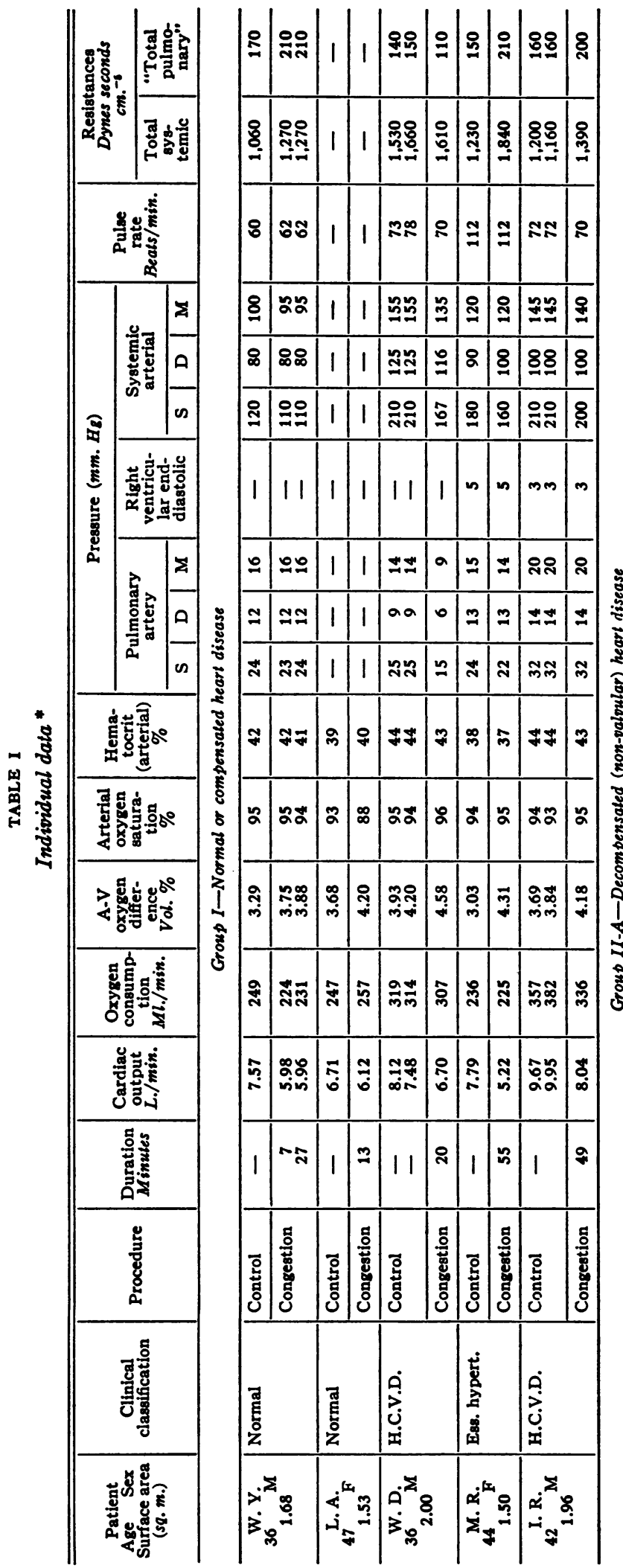

\begin{tabular}{|c|c|c|c|c|c|c|c|c|c|c|}
\hline $\mid \begin{array}{l}0 \\
\infty\end{array}$ & 요 & 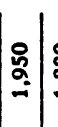 & 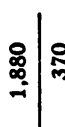 & 8 & 영음 & $\stackrel{R}{R}$ & 악욱 & 웅ㅇ & $\$$ & 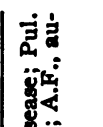 \\
\hline$\frac{0}{\frac{0}{m}}$ & 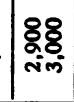 & ơ & 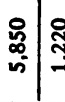 & $\int_{-i}^{8}$ & 유. & 总 & 赵: & $\frac{98}{92}$ & 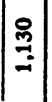 & 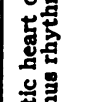 \\
\hline$\infty$ & 요 & $\stackrel{9}{0}$ & $\begin{array}{lll}0 & 0\end{array}$ & 8 & สळ & $\alpha$ & $\Xi \Xi$ & 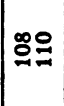 & $\stackrel{-10}{0}$ & 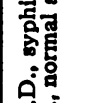 \\
\hline 8 & ఫ్సి & $\Phi$ & $\stackrel{\infty}{-}$ & 욯 & 脑 & 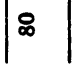 & $m=$ & 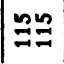 & $\cong$ & so \\
\hline : & 总号品 & $:$ & $:$ & $\mid \infty$ & \&R & R & 요 & RR & 2 & \\
\hline : & 品品 & సి| & สิ & 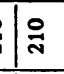 & 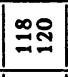 & 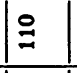 & $\mid$\begin{tabular}{l|}
$\infty$ \\
$\infty$ \\
$\approx$
\end{tabular} & జळ & $\stackrel{\infty}{\infty}$ & \\
\hline 웅 & nos & 요 & $\approx$ & $a$ & $\infty$ & $=$ & నిని| & నిని & 尺) & ذْ \\
\hline$\approx$ & 7우 & $\infty$ & $\infty$ & a & F⿻ & $\%$ & $7 \%$ & $\%$ & 7 & \\
\hline 7 & 이 & in & $\therefore$ & $\vec{m}$ & |so & a & $\mid$ స్లా & స్లె & $\approx$ & \\
\hline 2 & 우ำ & 8 & $\therefore$ & $n$ & ธี & 8 & $œ \infty$ & $\mathscr{0}$ & 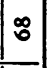 & \\
\hline$\$$ & $\$ 7$ & $\$$ & $\$ \$$ & 7 & מุ & $i n$ & సీల్ & | & के & 4 \\
\hline $\mathbf{\infty}$ & $\hat{\infty} \hat{\infty}$ & $\approx$ & ¿゙ & a & సేర్ & 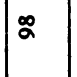 & ฉä & วณ & $\approx$ & 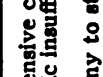 \\
\hline$\left|\begin{array}{l}8 \\
\infty \\
\infty\end{array}\right|$ & $\mid$ & $=$ & \begin{tabular}{ll}
0 \\
0 \\
\hdashline
\end{tabular} & 8 & రిఝ్ & $\mid \begin{array}{l}\overrightarrow{0} \\
\dot{0}\end{array}$ & 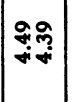 & 象早 & 7 & 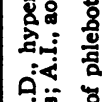 \\
\hline के & 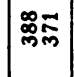 & ¿ & $\vec{a}$ & $\mathfrak{z}$ & สิสี & d & 誉 & 总商 & 离 & ت̈ष \\
\hline 包 & 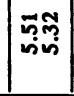 & 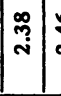 & 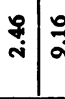 & శ్ & 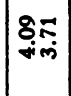 & $\dddot{m}$ & 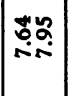 & | & $\stackrel{\infty}{\infty}$ & 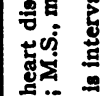 \\
\hline 1 & तf & 1 & $\stackrel{\circ}{i} 1$ & q) & 11 & $\begin{array}{r}0 \infty \\
+ \\
+\end{array}$ & 11 & $\bar{m}$ & 品 & 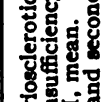 \\
\hline \begin{tabular}{|l}
$\overrightarrow{0}$ \\
0 \\
0 \\
0 \\
0
\end{tabular} & 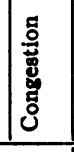 & \begin{tabular}{|l|} 
\\
\\
0 \\
0
\end{tabular} & 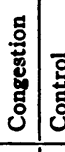 & 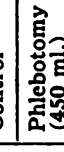 & $\begin{array}{l}\overline{0} \\
\vdots \\
0\end{array}$ & 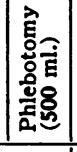 & 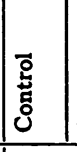 & 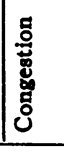 & 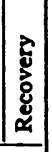 & 齿 \\
\hline & 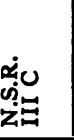 & 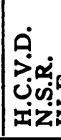 & 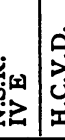 & 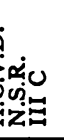 & 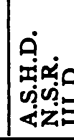 & & 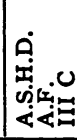 & & & sa \\
\hline & & $\therefore$ & & & & & ن & & & \\
\hline
\end{tabular}




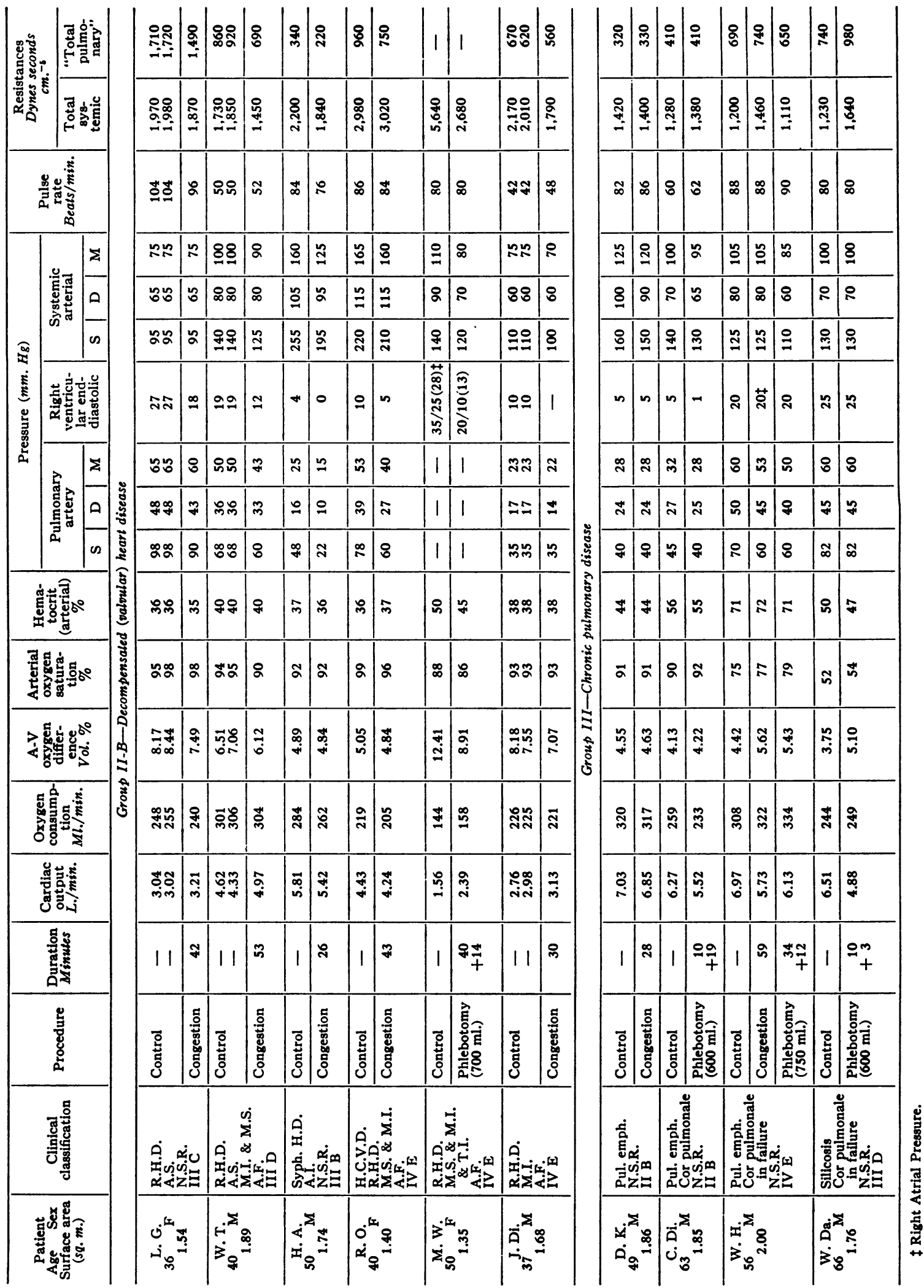


resistance opposing the right ventricle) was obtained from the following equation:

$$
R=\frac{P A_{m}}{C O} \times 1,332 \text { dynes seconds } \mathrm{cm} .^{-5}
$$

The "total systemic peripheral" resistance (actually, total resistance opposing the left ventricle) was obtained similarly :

$$
R=\frac{B A_{m}}{C O} \times 1,332 \text { dynes seconds } \mathrm{cm} .^{-6}
$$

where $\mathrm{PA}_{\mathbf{m}}=$ pulmonary arterial mean pressure, $\mathrm{mm}$. $\mathrm{Hg}$ $\mathbf{B A}_{\mathbf{m}}=$ brachial arterial mean pressure, $\mathrm{mm} . \mathrm{Hg}$

$\mathrm{CO}=$ cardiac output, $\mathrm{ml}$. per second

1332 = conversion factor from $\mathrm{mm}$. $\mathrm{Hg}$ to dynes per $\mathrm{cm}^{2}$

After preliminary practice, one or two control cardiac outputs were determined by the direct Fick method. Expired air was collected for two minutes in a Douglas bag while simultaneous blood samples were obtained at a constant rate from the brachial and pulmonary arteries. Immediately before and after the Fick procedure, pressures in the pulmonary artery, right ventricle, and brachial artery were determined. The volume of inspired air was measured by a Tissot spirometer, which contained a supply of outdoor air. Oxygen and carbon dioxide concentrations in the expired air were determined by the Haldane method (6) with duplicated determinations required to agree within 0.03 per cent. Blood samples were analyzed for oxygen content, capacity, and saturation by the method of Van Slyke and Neill (7) with duplicate determinations required to agree within 0.10 vol. per cent. Possible slight errors in blood oxygen contents due to dilution in obtaining blood samples through the catheter were corrected as follows:

Corrected venous oxygen content

$$
=\text { Observed venous oxygen content } \times \frac{\text { art. hct. }}{\text { ven. hct. }}
$$

In fourteen patients the cardiohemodynamic measurements were repeated 7 to 68 minutes after application of venous congesting cuffs high on the thighs at $70 \mathrm{~mm} . \mathrm{Hg}$. In six patients similar measurements were made from 3 to 20 minutes after the completion of a 450 to 750 milliliter phlebotomy. The venesections were accomplished over a period of 10 to 40 minutes. A few patients in whom the oxygen consumption during the control and procedure periods did not check within 10 per cent were excluded from the study. Likewise, patients in whom the cardiac output during the control periods varied more than 10 per cent were also excluded from the study (4).

\section{RESULTS}

The cardiovascular responses to venous congestion of the extremities and phlebotomy are summarized in Table $I$ and the means are shown in Table II with a statistical analysis.

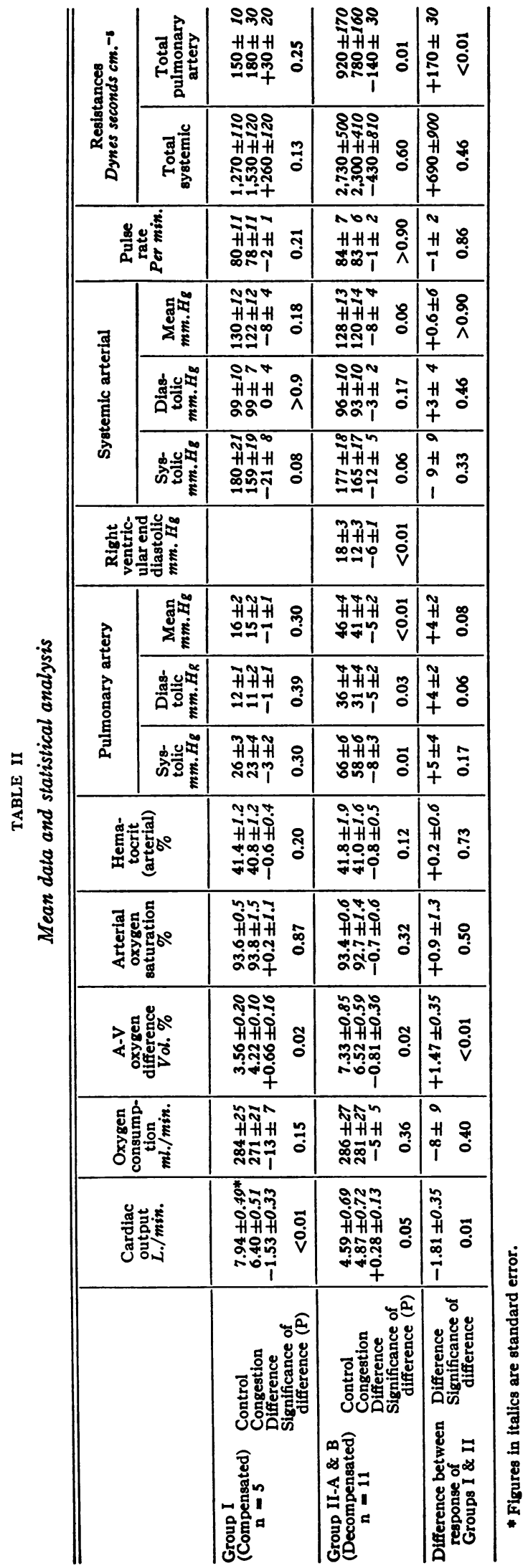




\section{Group I-Patients without heart failure}

A. Cardiac output and oxygen measurements. All five patients showed falls in cardiac output, four of which were greater than 10 per cent. The mean decrease in cardiac output was 1.53 liters per minute which was highly significant statistically. This was associated with a mean increase of 0.66 vol. per cent in the arterio-venous oxygen difference, a change which was also highly significant. The oxygen consumption, arterial oxygen saturation, hematocrit, and pulse rate did not change significantly.

$B$. Vascular pressures. In two patients (M. R., I. R.) in whom it was measured, the end-diastolic right ventricular pressure did not change measurably from the control normal values during congestion of the limbs despite a decrease in the cardiac output. Only one patient (W.D.) showed a physiologically significant decrease in the pulmonary arterial pressure. The group as a whole showed no significant change in the pulmonary arterial pressure. There was a tendency for the peripheral arterial pressure to decrease, but the change was not statistically significant for the group. Indeed, only one severely hypertensive patient, W. D., had an appreciable drop in blood pressure.

C. Vascular resistance. Both the "total pulmonary" and "total systemic" resistances showed slight but not significant increases. The direction of these slight changes was such as to tend to maintain constancy of pressure with the change in cardiac output. In only one patient, W. D., who had a considerable fall in arterial pressure did a correspondingly large change in the systemic vascular resistance occur.

\section{Group II-Patients with heart failure}

The decompensated patients with valvular and non-valvular heart disease responded similarly to stimuli which reduced the "effective blood volume." The averages presented in Table II include both types of patients.

A. Cardiac output and oxygen measurements. On the average there was a slight but statistically significant increase in cardiac output of 0.28 liters per minute. This change was associated with a mean decrease of 0.81 vol. per cent of the arteriovenous oxygen difference, which was also signifi- cant statistically. The direction of these responses was opposite to that of the compensated patients, and the difference between the responses of the two groups was highly significant statistically. The oxygen consumption, arterial oxygen saturation, hematocrit, and pulse rate did not change significantly.

$B$. Vascular pressures. Initially the right ventricular end-diastolic pressures were elevated in almost all the patients. Venous congestion of the extremities or venesection produced a mean decrease of $6 \mathrm{~mm} . \mathrm{Hg}$ in the right ventricular diastolic pressure in the group, a highly significant change statistically and physiologically. The pulmonary arterial systolic, diastolic, and mean pressures likewise showed significant decreases of a similar order of magnitude. The pulmonary arterial pressures in these patients changed in the same direction as in the compensated group but to a significantly greater degree. On the average there was an $8 \mathrm{~mm}$. $\mathrm{Hg}$ decrease in peripheral mean arterial pressure, a change which was not statistically significant.

An interesting illustration is M. W., a patient with mitral valvular heart disease and functional tricuspid insufficiency. This patient had the largest increase in cardiac output of the entire group after venesection, and this was associated with the greatest reduction in mean right atrial pressure. After phlebotomy the mean pressure and the amplitude of pulsations in the right atrial pressure tracing, as observed in Figure 1, were reduced, possibly due to a decrease in the volume of blood regurgitated through the tricuspid valve. The cardiac output had increased 53 per cent.

However, not all the patients in the group who had increases in the cardiac output during these maneuvers had decreases in the vascular pressures. Conversely, not all the patients who had significant reductions in the right ventricular diastolic and the pulmonary arterial pressures had significant increases in cardiac output. Furthermore, in those patients in whom there were simultaneously measured increases in cardiac output there was no consistent correlation with the degree of reduction in the right ventricular diastolic and pulmonary arterial pressures.

C. Vascular resistances. The "total pulmonary" resistance decreased, on the average, 14 per cent, a highly significant statistical change for the 
EzFone PHLEBOTOWY

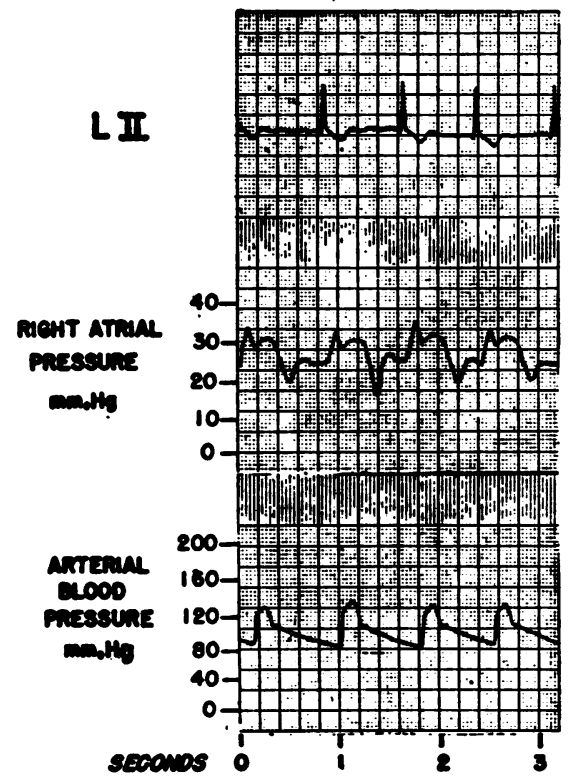

AFTER PHLEBOTONY

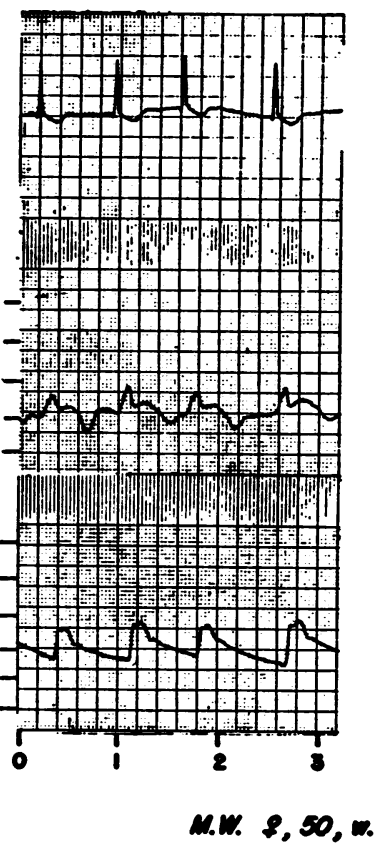

Fig. 1. Recording of the Right Atrial Pressure in Patient (M. W.) with Rheumatic Heart Disease and Functional Tricuspid Insufficiency Showing the Reduction in Mean Pressure and Amplitude of Pulsations after Phlebotomy

This change may be due to reduction in degree of regurgitation. This patient likewise had a marked increase in cardiac output.

group. The total systemic resistance also decreased 16 per cent, but the change lacked statistical significance. The vascular resistances changed in a direction such that the blood pressure tended to remain at a constant level with the simultaneous increase in cardiac output. The decreases in resistances in this group contrasted with the increases in the compensated patients. The difference between the responses of the "total pulmonary" resistance of the two groups was highly significant statistically.

\section{Group III-Patients with pulmonary emphysema with or without heart failure}

The responses to venesection of two patients with heart failure due to pulmonary heart disease were different from those with heart failure due to forms of heart disease generally classified as "low output failure." Therefore, these patients as well as two others with actual or potential cor pulmonale without heart failure are presented sep- arately from the other groups. The small number of patients studied rendered statistical analysis of the results impractical.

The two patients (D. K., C. Di.) in this group without heart failure had elevated pulmonary arterial pressure, distinguishing them from the patients in Group I. Both of these patients had reductions in cardiac output during limb congestion (D. K.) or after phlebotomy (C. Di.). However, in patient $\mathrm{C}$. Di., the decrease in cardiac output was proportionate to a fall in the oxygen consumption without an appreciable change in the mixed arterio-venous oxygen difference. In this patient there was a fall in the right ventricular end-diastolic and pulmonary arterial pressures, while in patient $D$. K., there were no changes in these pressures.

The two patients (W. H., W. Da.) in this group with congestive failure had appreciable decreases in cardiac output after phlebotomy with no changes in the right ventricular end-diastolic pressure. Patient W. H., showed a moderate 
decrease in the pulmonary and brachial arterial pressures. In contrast, patient W. Da. had no fall in the pulmonary and brachial arterial pressures even in the presence of a marked reduction in cardiac output and hematocrit. There was a very slight tendency for the arterial oxygen saturation to increase after phlebotomy $(+1.7$ per cent), but the change lacked statistical significance $(P=0.10)$. The oxygen consumption, hematocrit, and pulse rate did not change appreciably in the group as a whole.

\section{DISCUSSION}

Normal subjects, patients with compensated hypertensive cardiovascular disease, and patients with cor pulmonale with or without congestive failure all appeared to have a similar response in cardiac output after venesection or venous congestion of the limbs, procedures which are believed to produce a reduction in the "effective blood volume." This response was characterized by a decrease in cardiac output which was usually not associated with measurable changes in the right ventricular end-diastolic pressure. In contrast, patients with congestive heart failure due to hypertension, coronary, or valvular heart disease had usually a slight increase, occasionally no change, or rarely a slight decrease in cardiac output. Again these changes in cardiac output were observed in individual cases to be independent of changes in the right ventricular end-diastolic pressure, which either remained the same or decreased. The group as a whole, however, showed a significant reduction in the right ventricular diastolic pressure.

Collateral studies in this laboratory have shown that patients with different types of congestive failure also may show characteristic changes in cardiac output in response either to exercise (6) or to the acute infusion of saline solution (7). Thus, in response to these stimuli, normal subjects, patients with compensated heart disease, and patients with cor pulmonale in failure usually increase their cardiac outputs. Patients with hypertension, coronary artery, and valvular heart disease with congestive failure have relatively fixed cardiac outputs which do not increase normally after exercise or saline infusion. Furthermore, as shown in the present study, the cardiac output in such patients usually does not decrease normally after stimuli which are believed to cause reductions in the "effective blood volume." The observations suggest that the heart in hypertensive heart disease without congestive failure and in cor pulmonale without or even with congestive failure may have greater reserve and may be more responsive to changes in right heart filling, while in the patients with so-called "low output failure" the heart is usually less responsive to changes in right heart filling.

The responses in cardiac output in the present study are similar to those previously reported (1). However, increases in cardiac output in patients with "low output" congestive heart failure were observed less frequently, and when observed, were smaller in magnitude than those found by Howarth, McMichael, and Sharpey-Schafer (3). An increase in cardiac output has been reported to occur occasionally after phlebotomy in patients with chronic cor pulmonale and severe congestive heart failure (8). By contrast, in our two cases of chronic pulmonary disease with severe congestive failure the cardiac output fell after phlebotomy. As just mentioned, in a larger series of patients with cor pulmonale and congestive failure, a normal increase in cardiac output was frequently found in response to exercise or to an acute infusion of hypertonic saline solution (9). Warren, Brannon, Stead, and Merrill (2) found that the response of cardiac output depends not solely upon changes in the right atrial pressure. McMichael, and his co-workers $(1,3,10)$ have also observed falls in the right atrial pressure after reduction in "effective blood volume." Measurements of mean right atrial pressure, however, may not accurately reflect right ventricular filling pressure. The measurements of the right ventricular end-diastolic pressure obtained in the present study did not show a uniform decrease after venesection or trapping of blood in the extremities by venous congestion in patients with "low output" type of failure. Furthermore, the response in cardiac output was found to be independent of the changes in the right ventricular end-diastolic pressure. These results, however, do not necessarily bear upon the relevancy of Starling's Law to the intact human heart since neither the right ventricular end-diastolic volume nor the pericardial pressure was measured. The 
data suggest, however, that factors other than right heart filling are also important in determining cardiac output. These factors might, and undoubtedly do, include some or all of the following: 1) the degree or "stage" of congestive failure and the associated state of myocardial metabolism. This factor would include those considerations ordinarily implied by the terms "myocardial reserve," "cardiac fatigue," and "cardiac tone"; 2) the involvement in the failure of one or more chambers of the heart. Thus, failure of the left and right ventricles might well behave differently than failure of either one alone; 3 ) the amount of pulmonary vascular and even of peripheral vascular disturbances associated with the failure; 4) the amount of mechanical defect such as valvular incompetence associated with the failure.

The main factors controlling pulmonary arterial pressure (in relation to intrapleural pressure) are cardiac output, pulmonary arteriolar resistance, and resistance to flow through the left side of the heart. Since the latter two measurements were not obtained in this study they cannot be evaluated. However, it can be stated that the reductions in cardiac output observed in normal subjects and in patients with cor pulmonale were not consistently associated with falls in pulmonary arterial pressure. In patients with left ventricular failure who had rises in cardiac output after phlebotomy the reduction in pulmonary arterial pressure was attributed partly to a decrease in resistance to flow because of a lower left atrial pressure. However, since "wedge" or "pulmonary capillary" pressures were not taken because of the already great complexity of the procedure, no definite observations bearing on this point are available.

\section{CONCLUSIONS}

During venesection or venous congestion of the limbs (acute reductions of "effective blood volume"),

1. Normal subjects, patients with compensated cardiovascular disease, and patients with cor pulmonale with or without failure had a fall in cardiac output.

2. Patients with congestive heart failure due to valvular, hypertensive, or coronary heart disease usually had a slight rise, occasionally no change, or rarely a slight fall in cardiac output.
3. The response in cardiac output was not necessarily accompanied by a change in the right ventricular end-diastolic pressure.

4. A reduction in the pulmonary arterial pressure was not consistently observed. Decreases in cardiac output in some patients may explain the fall in pulmonary arterial pressure.

R.

\section{ACKNOWLEDGMENT}

The authors gratefully acknowledge the technical assistance of Miss Janice McMorrow, Miss Adele Rymut, and Miss Margaret Sullivan.

\section{REFERENCES}

1. McMichael, J., and Sharpey-Schafer, E. P., Cardiac output in man by a direct Fick method. Effects of posture, venous pressure change, atropine, and adrenaline. Brit. Heart J., 1944, 6, 33.

2. Warren, J. V., Brannon, E. S., Stead, E. A., Jr., and Merrill, A. J., The effect of venesection and the pooling of blood in the extremities on the atrial pressure and cardiac output in normal subjects with observations on acute circulatory collapse in three instances. J. Clin. Invest., 1945, 24, 337.

3. Howarth, S., McMichael, J., and Sharpey-Schafer, E. P., Effects of venesection in low output heart failure. Clin. Sc., 1946, 6, 41.

4. Harvey, R. M., Ferrér, M. I., Cathcart, R. T., Richards, D. W., Jr., and Cournand, A., Some effects of digoxin upon the heart and circulation in man. Digoxin in left ventricular failure. Am. J. Med., 1949, 7, 439.

5. Gorlin, R., Haynes, F. W., Goodale, W. T., Sawyer, C. G., Dow, J. W., and Dexter, L., Studies of the circulatory dynamics in mitral stenosis. II. Altered dynamics at rest. Am. Heart J., 1951, 41, 30.

6. Haldane, J. S., Methods of Air Analysis. London, Griffin, 1912.

7. Van Slyke, D. D., and Neill, J. M., The determination of gases in blood and other solutions by vacuum extraction and manometric measurement. I. J. Biol. Chem., 1924, 61, 523.

8. Judson, W. E., Hollander, W., Hatcher, J. D., Halperin, M. H., and Friedman, I., The effects of exercise in the supine position on the cardio-renal hemodynamics and excretion of electrolytes and water. To be published.

9. Hollander, W., Judson, W. E., and Friedman, I., Cardiovascular responses to hypertonic saline in patients with and without congestive heart failure. To be published.

10. Howarth, S., McMichael, J., and Sharpey-Schafer, E. P., Effects of oxygen, venesection and digitalis in chronic heart failure from disease of the lungs. Clin. Sc., 1946, 6, 187. 